\title{
O QUE NÃO TEM REMÉDIO, REMEDIADO ESTÁ?
}

\author{
Renata Guarido ${ }^{*}$ \\ Rinaldo Voltolini ${ }^{*}$
}

RESUMO: Temos observado um aumento significativo na prescrição de medicamentos psiquiátricos para toda sorte de sofrimentos cotidianos. Sabemos que as crianças não têm sido poupadas dessa lógica de tratamentos. A escola, por sua vez, tem apelado intensamente ao saber médico para "corrigir" os problemas apresentados por seus alunos. A prática descrita brevemente está sustentada por uma biologização cada vez mais bem-sucedida de nossa condição humana, ou seja, parece que chegou o tempo de o homem viver de perto o mito do criador, sustentado pelo controle da bioquímica e da genética de nosso organismo. Como efeito dessa biologização temos um silenciamento do sujeito em benefício da amplificação do lugar ocupado por seu organismo. Neste trabalho, pretendemos discutir o impacto dessa lógica de tratamentos para a prática nas escolas. O que pretendemos destacar aqui é que se a bioquímica responde ao porquê o menino aprende ou não aprende, e o remédio se torna um instrumento imprescindível na aprendizagem da criança, o professor "não tem mais nada a ver com isto", no duplo sentido que a expressão indica: o de desresponsabilização e o de impotência.

Palavras-chave: Psicanálise; Educação; Medicalização

\section{WHAT CANNOT BE CURED MUST BE ENDURED?}

ABSTRACT: A significant increase in the prescription of psychiatric medication for all kinds of daily suffering is observed, and children have not been prevented from this treatment. Schools, on their turn, have intensively appealed to the doctor's knowledge to 'correct' the problems their students present. This briefly described practice is sustained by an ongoing well succeeded biologization of our human condition, that is, it seems that the time has come for man to experience the creator myth, supported by the biochemical and genetic control of our organisms. As an effect of this biologization, the subject is silenced for the benefit of the enlarge-ment of the room his or her body occupies. A discussion on the impact of this logic of treatment practiced in schools is developed focusing on a crucial question: would bio-chemistry answer the question why a child learns or not, would medicine play a main role in the child learning process, would a teacher 'have nothing to do with it' in the two senses the expression suggests: a process of irresponsibility and a status of impotence?

Keywords: Psychoanalysis; Education; Medicalization

\footnotetext{
* Psicanalista e mestre em Educação pela Faculdade de Educação da USP.E-mail: reguarido@ig.com.br

** Psicanalista e professor doutor da Faculdade de Educação da USP. E-mail: rvoltolini@uol.com.br
} 
A idéia de que um fenômeno - a dificuldade de aprender - tenha como causa o que vem sendo considerado doença - hiperatividade, déficit de atenção, dislexia, depressões na infância, etc. - não mais parece surpreender: está em capas de revistas semanais, nas revistas dirigidas aos pais, nas páginas dedicadas às boas novas científicas de qualquer jornal.

O saber médico difundido na mídia leiga atualmente apresentase na escola de forma marcante. É comum que professores e coordenadores professem diagnósticos diante da observação de certos comportamentos das crianças, especialmente de Transtorno de Déficit de Atenção e Hiperatividade (TDAH), e as encaminhem para avaliação psiquiátrica, neurológica e/ou psicológica. É comum também que agentes das equipes escolares insistam em perguntar aos pais, quando se encontram diante de alguma manifestação não conhecida (ou não desejada) de uma criança que está em tratamento, se ela foi corretamente medicada naquele dia. Tais procedimentos nos permitem entrever que os professores não somente procuram nas descrições sobre os quadros dos transtornos mentais, difundidas pela mídia, material para classificarem seus alunos, como estão crentes de que a variação no uso do remédio é responsável pela variação dos comportamentos e estados psíquicos das crianças, reduzindo a relação desta com mudanças ou experiências no cotidiano escolar.

Os profissionais das escolas parecem também esperar que um diagnóstico proferido por um especialista permita encontrar a metodologia de ensino correta para, enfim, fazer sair da ignorância e da inadequação as crianças e jovens que têm diante de si. No entanto, quando finalmente conseguem receber tais diagnósticos, os professores não encontram a esperada receita pedagógica de como ensinar, como fazer aprender e, mais uma vez, se frustram. Buscam, então, cursos de formação, adiando mais um pouco o tempo em que saberão como fazer para empreender a tarefa que lhes cabe: educar as crianças nas escolas.

Podemos reconhecer, no contato cotidiano com os professores e outros agentes das equipes escolares, algo que há muito vem sendo trabalhado por autores críticos da apropriação e da presença do discurso especialista no cotidiano escolar. Patto (1993), por exemplo, analisa como as explicações psicológicas sustentaram a culpabilização das crianças e das famílias pelo fracasso escolar, bem como serviram à manutenção das divisões de classe e da ideologia burguesa. Também reconhecemos a demanda por um diagnóstico de um especialista como efeito do que Lajonquière (1999) denominou o discurso psicopedagógico hegemônico. 
E, remetendo-nos a Foucault (1987), poderíamos tomar a mesma demanda como resultado das práticas disciplinares que ganharam, na modernidade, a eficácia de caracterizar os indivíduos, classificando-os, localizando-os e registrando-os numa curva que identifica a variação entre o normal e o anormal.

O fato de o saber médico circular, nos dias de hoje, intensamente no âmbito leigo já é em si revelador, evidencia o estatuto de verdade que esse saber ganha na modernidade. Assim, focamos nosso interesse naquilo que tem sido nomeado de medicalização - dos discursos, da vida, dos processos de escolarização.

As escolas não ficaram fora desse processo e a compreensão desse fato depende de um percurso mínimo, que nos proporemos neste texto: primeiro, da medicalização enquanto processo histórico; segundo, da concepção da infância que, em seus giros, tornou possível a inserção da criança no universo mórbido das patologias mentais para as quais se recomenda atualmente o uso da medicação.

\section{MEDICALIZAÇÃO}

O conceito de medicalização foi utilizado em diversos estudos, especialmente a partir da década de 70 do século XX, para tratar de uma maneira com base na qual os "problemas de aprendizado das crianças" foram freqüentemente traduzidos. Medicalizar um fenômeno teve, tradicionalmente, o sentido geral de reduzir as problemáticas sociopolíticas a questões de foro privado, individual. Além disso, se o objeto da medicina foi, até certo momento histórico, quase que exclusivamente a investigação sobre as doenças, suas causas e suas terapêuticas, medicalizar um fenômeno ou acontecimento significava patologizá-lo.

De maneira geral, a crítica dirigida por diversos autores à medicalização diz respeito à redução de questões amplas - que envolveriam, em sua análise, diversas disciplinas (sociologia, antropologia, psicologia, economia, ciências políticas, história, medicina, etc.) - a um único domínio metodológico disciplinar: a medicina. A medicalização foi então tomada como expressão da difusão do saber médico no tecido social, como difusão de um conjunto de conhecimentos científicos no discurso comum, como uma operação de práticas médicas num contexto não terapêutico, mas político-social.

Vale aqui ressaltar que medicalização é antes um conceito que pode ser aplicado às diversas esferas da vida, associado a uma prática dis- 
cursiva que revela a forte presença do saber médico no conjunto dos discursos sobre o homem, sua natureza e suas vicissitudes, a partir do século XIX.

Gori e Del Volgo (2005), por exemplo, pensam a medicalização da existência como decorrendo não somente do estatuto do saber médico na modernidade, mas também como conseqüência das transformações próprias a esse contexto histórico, especialmente no que diz respeito ao lugar ocupado pela tecnologia científica no mundo moderno, bem como às mudanças ocorridas nos campos da ética e da política. Ou seja, os autores situam a medicalização como pertencente à condição humana na modernidade e consideram que esta se constitui numa organização de práticas e formulações epistemológicas próprias de uma ciência experimental, que configura uma técnica de apreensão dos fenômenos humanos e, ainda, a compreendem como inserida no interior das práticas mercantilizadas de troca humana no mundo moderno.

Assim, salientamos uma apreensão que vai além de uma concepção da medicalização como forma de tradução de problemáticas político-sociais como particularidades individuais, como é recorrente no que diz respeito às análises da relação entre medicina e educação, mas que a insere no conjunto da ideologia moderna e na formação do homem moderno, no que diz respeito à forma com que significa seu corpo, seu lugar político, suas vivências subjetivas e tudo o que decorre da difusão da medicina no ideário moderno.

Esta cultura "moderna" priva simultaneamente o sujeito humano de seu valor subjetivo, de seu "cuidado de si" (...) e de sua função política. Nesta privação da ação política e da obra subjetiva, o homem contemporâneo se vê condenado a uma espiral de reivindicações sociais e de consumo solitário dos bens sociais. Entre estes bens sociais, dos quais ele se reconhece proprietário, consumidor e usuário de pleno direito, por uma legislação um tanto importuna, figura sua saúde. (GORI; DEL VOLGO, 2005, p. 11, Grifos dos autores) [tradução livre]

(...) nós falamos aqui da "medicalização da existência" como de uma construção social e intersubjetiva que pertence, da cabeça aos pés, em sua gênese como em sua função, a uma estrutura da cultura moderna e ao mal-estar por excelência desta civilização. (ibidem, p. 21, Grifos dos autores) [tradução livre]

Trata-se, assim, de reconhecer um discurso que constitui o homem no mundo moderno; ele é, pois, indissociável de uma percepção medicalizada de si, dos acontecimentos que o envolvem, sociais ou particulares. 


\section{OLHAR SOBRE AS CRIANÇAS E AS FAMÍLIAS}

As mudanças modernas que permitiram a constituição de um sentimento da infância, analisadas no estudo já muito conhecido de Philippe Ariès (1981), constituíram tanto um olhar para a particularidade da criança e do tempo da infância quanto também para o futuro que determinariam. $\mathrm{O}$ novo sentimento da infância se combinou à configuração de um novo adulto nas modernas idealizações das nações em construção. Este adulto que iria fazer parte do conjunto da população saudável, letrada e produtiva, passou a ser perseguido (a partir do final do século XVIII), desde suas primeiras experiências de vida, encontrando nestas seu bom destino ou a desgraça de seu futuro.

Ao problema "das crianças" (quer dizer de seu número no nascimento e da relação natalidade - mortalidade) se acrescenta o "da infância" (isto é, da sobrevivência, dos investimentos necessários e suficientes para que o período de desenvolvimento se torne útil, em suma, da organização desta "fase" que é entendida como específica e finalizada). Não se trata, apenas, de produzir um melhor número de crianças, mas de gerir convenientemente esta época da vida. (FOUCAULT, 1982, p. 199).

Um dos projetos modernos, criado com o novo sentimento de infância, diz respeito ao esforço de civilidade destinado às crianças e que encontra nos progressos da escolarização espaço privilegiado de debate. As interferências dos adultos, destinadas tanto a civilizar quanto a letrar as crianças, passaram a ocorrer, ao longo do século XIX, especialmente nos colégios e as famílias, aos poucos, se constituem como espaço privado, núcleo da educação privada das crianças.

Aos ideais da formação em termos morais, comportamentais, de letramento somaram-se também hábitos higiênicos de alimentação, de asseio, de contato físico e de trocas afetivas no interior das famílias, bem como das escolas; o saber médico difundiu-se socialmente como conhecimento necessário para configurar pressupostos e sustentação de práticas de cuidado e educação que permitissem que as crianças tivessem um desenvolvimento adequado e uma vida saudável.

Um conjunto complexo de disciplinas se organizou em torno da criança, da família e da infância ao longo dos dois últimos séculos; um novo jogo de idéias e práticas passou a sustentar as intervenções destinadas a fornecer as referências modernas de cuidado e moralização das 
crianças. E, neste conjunto, estiveram envolvidos, especialmente, pediatras, psiquiatras, psicólogos e pedagogos, reunidos para orientar famílias e escolas.

Algumas referências tornaram-se fundamentais, no que diz respeito ao cuidado da infância, como tempo de vulnerabilidade, de preparo e as intervenções dirigidas às escolas e famílias tiveram raízes, em geral, nas teorias higienistas - bem como nas idéias preventivas da higiene mental -, nas teorias médicas sobre a degeneração, nas concepções da puericultura e no desenvolvimento das técnicas e dos conceitos da psicometria e da psicologia do desenvolvimento (PATTO, 1999; COSTA, 2004; MOYSES, 2001; LEGANI; ALMEIDA, 2004). As intervenções destinadas ao cuidado desse tempo de preparo pautaram-se por uma definição de prevenção e moralização das crianças e das práticas educativas.

A criança e a infância tornam-se objeto de estudo, e a medicina e a psicologia tornam-se disciplinas centrais nas investigações sobre o desenvolvimento e o psiquismo, influenciando fortemente as práticas pedagógicas desde então, dando estatuto científico às teorizações sobre a criança - seu desenvolvimento e seus desvios - e para a infância como tempo especialmente importante na formação do homem. A infância torna-se um tempo de preparo, de passagem. Por conseqüência, aquilo que, durante este tempo, ocorre, concorre para a forma, as habilidades, a autonomia, a liberdade que um adulto poderá ter.

Num sistema de disciplina, a criança é mais individualizada que o adulto, o doente o é antes do homem são, o louco e o delinqüente mais que o normal e o não-delinqüente. (...) Todas as ciências, análises ou práticas com radical "psico", têm seu lugar nessa troca histórica dos processos de individualização. O momento em que passamos de mecanismos histórico-rituais de formação da individualidade do homem memorável pela do homem calculável, esse momento em que as ciências do homem se tornaram possíveis, é aquele em que foram postas em funcionamento uma nova tecnologia do poder e uma nova anatomia política do corpo. (FOUCAULT, 1987, p. 161)

A primeira via de difusão coletiva das ações médicas destinadas ao cuidado das crianças, do final do século XIX ao início do século XX, enfocou o controle dos altos índices de mortalidade nas cidades. $\mathrm{O}$ imenso número de mortes das crianças estava vinculado, segundo análises dos médicos higienistas, a alguns fatores, mas em especial às condições de nutrição observadas tanto nas famílias burguesas quanto nas populares. A prática de aleitamento pelas amas-de-leite foi particularmente atacada pelo grupo higienista (DONZELOT, 2001). 
A alta mortalidade das crianças também se associava a uma prática de numerosos abandonos das crianças filhas de famílias pobres, órfãs, bem como filhas bastardas da burguesia. A rede de assistência às crianças abandonadas já havia se formado desde o século XVII e seu aumento foi significativo ao longo dos séculos XVIII e XIX, especialmente nas cidades, onde se observava um enorme crescimento populacional (com a migração vinda do campo, fruto da recente industrialização) e um aumento significativo da pobreza urbana. Os gastos do Estado já estavam envolvidos com a manutenção dessa rede de assistência, realizada por instituições públicas bem como por religiosas.

Contra o excesso de mortes, os gastos com a assistência, o uso das crianças como força de trabalho, o abandono, uma mudança de hábitos se fazia necessária. Um dos eixos de ação do Estado contava com a defesa e a difusão das propostas higienistas. Assim é que a precariedade das práticas de nutrição nas famílias burguesas e a necessidade de economia dos gastos sociais para com as famílias populares fizeram da associação entre a medicina e o Estado uma forma de melhoria das condições de saúde, de garantia de sobrevivência dos indivíduos que serviriam para a manutenção da economia e da nação, bem como permitiu uma economia social, diminuindo, por meio de uma rede de filantropia, os altos custos estatais com a manutenção das crianças abandonadas. Duplo agenciamento da saúde: contribuir para uma economia privada dos costumes, garantindo uma assistência pública enxuta (DONZELOT, 2001).

A infância, a cultura familiar e as formas de escolarização foram os alvos mais visados pela ação médica-higiênica, tanto na Europa quanto no Brasil; foi no contexto da escola e da família que as práticas higiênicas tiveram maior êxito; foi neste viés, ou seja, o da educação, que a junção entre a medicina e o Estado esteve presente - numa medicalização das práticas escolares e das relações familiares.

A família não deve ser mais apenas uma teia de relações que se inscreve em um estatuto social, em um sistema de parentesco, em um mecanismo de transmissão de bens. Deve se tornar um meio físico denso, saturado, permanente, contínuo que envolva, mantenha e favoreça o corpo da criança. (...) A família - aparelho estrito e localizado de formação - se solidifica no interior da grande e tradicional família-aliança. (...) Em todo caso, desde o fim do século XVIII, o corpo sadio, limpo, válido, o espaço purificado, límpido, arejado, a distribuição medicamente perfeita dos indivíduos, dos lugares, dos leitos, dos utensílios, o jogo do "cuidadoso" e do "cuidado", constituem algumas das leis morais essenciais da família. E, desde esta época, a família se tornou o agente mais constante de medicalização. (FOUCAULT, 1982, p. 199) 
A concepção moderna sobre a infância, entendida como tempo de desenvolvimento e preparo, justificava e legitimava as práticas higienistas; a infância passava a ser vista como tempo profícuo de prevenção das doenças debilitadoras da saúde, das doenças mentais, bem como da criminalidade. A fim de responder a um conjunto de idéias que passou a vi-gorar na medicina sobre os efeitos da herança biológica, especialmente no que diz respeito aos problemas mentais e delinqüenciais da juventude, as crianças passam a ser necessariamente assistidas em seu desenvolvimento.

À idéia do que seja uma criança e seu desenvolvimento somouse a possibilidade de mensurar suas capacidades e funções, o que permitiu uma individualização das classificações e distinções propostas às crianças. As escalas de inteligência desenvolvidas por Binet e Simon tiveram aqui importante influência no que diz respeito à individualização do olhar sobre a particularidade de cada criança, o que serviu em muito para os ideais de uma escolarização que pretende oferecer a cada um o que lhe seja necessário para otimizar suas capacidades, tornando a proposta do "ensino individualizado" um ideal do século XX. A aplicação das escalas de mensuração da capacidade intelectual respondia não somente aos regimentos da psicologia nascente, mas também prezava por garantir a educação das diversas categorias da população infantil, distinguindo os que podiam desenvolver certa intelectualidade daqueles para quem se criavam serviços escolares profissionalizantes ou especiais.

Higienismo, puericultura, psiquiatria da criança, psicometria, pedagogia: a combinação dessas disciplinas esteve claramente representada nas práticas médico-psicopedagógicas de intervenção sobre a infância anormal e os problemas enfrentados pelas crianças nas propostas escolares modernas.

Centros de assistência, clínica de aconselhamento, serviços médico-escolares, escolarização especial para as crianças anormais foram alguns dos empreendimentos que puseram em prática as teses formuladas sobre as fases de desenvolvimento, as heranças familiares, as funções da inteligência. Resulta que a divisão normal/anormal se instala como referência nas classificações que receberam as crianças a partir de então e continua a ser esta uma divisão potente para justificar a criação de terapêuticas e mecanismos especiais de escolarização ao longo de quase dois séculos.

Os problemas de aprendizado, antes de estarem vinculados ao estudo da própria institucionalização da escolarização, foram aos poucos 
inscritos na ordem de problemas individuais, de herança e de caráter, além, é claro, das capacidades intelectuais de cada aluno.

A ordem da saúde/doença é o espectro amplo no qual as queixas dirigidas ao campo médico podem ser situadas, interpretadas, bem como tratadas. No entanto, as questões do desenvolvimento não estão propriamente colocadas quando inseridas na divisão saúde/doença; sabe-se, no interior da medicina, que o espaço transitório e "em desenvolvimento" do tempo da infância impõe re-situar os fenômenos do desenvolvimento e suas perturbações, de forma a considerar as variações próprias do tempo da infância. Incorporar as variações da expressão desse desenvolvimento implicou a associação da medicina com outras disciplinas, especialmente com a psicologia. A idéia de uma individualização dos cuidados na escola pode ser tomada como expressão dessa aproximação entre medicina e psicologia.

Essa tendência de psicologização do ensino contribuiu, em primeiro lugar, para a idéia de que um bom cuidado dos professores para com as crianças seria fruto de uma "atenção individual"; além disso, surtiu efeitos de responsabilização do indivíduo por suas dificuldades, valorizando a consideração de "questões internas" ou da qualidade das relações familiares como causas do "desajuste" e do não-aprendizado; e ainda, forçou uma associação do binômio saúde/doença a outro, mais ideologicamente marcado, o da normalidade/anormalidade. Reconhecemos aqui, como efeito de uma prática higienista e moralizadora das condutas para a formação de um ser saudável e produtivo - aliada à psicometria dos alunos -, uma patologização dos problemas de aprendizado. A difusão dos saberes médicos e psicológicos influenciou a prática pedagógica por boa parte do século XX. Seus efeitos estigmatizantes e de exclusão já foram denunciados por diversos autores.

A partir dos anos 1970, vimos se estabelecer uma visão crítica sobre essa via de medicalização (a que se aliou uma forma de psicologização da escola), do ponto de vista de seus efeitos - muitas das doenças diagnosticadas nas crianças foram criticamente (re)inscritas em seu processo de escolarização.

$\mathrm{Na}$ passagem do século XX ao XXI, parece-nos que uma variação dessa influência tem ocorrido, fruto dos novos conhecimentos produzidos pelas biociências e neurociências para a compreensão do homem. 


\section{A BIOLOGIZAÇÃO DA VIDA: SE O CORPO FALA, O SUJEITO CALA}

O avanço da ciência não pode ser medido por sua lógica interna. As questões que animam a pesquisa científica não são, de modo algum, exclusivamente geradas pela própria dinâmica criada por seus resultados anteriores, como se nada mais houvesse além da reflexão lógica e da racionalidade que o cientista possui. O desejado ideal, para alguns, da neutralidade científica, ou da pesquisa pura, desinteressada, não passa de um mito, como todos sabem.

Não deveríamos, entretanto, desprezar os mitos, em particular o criado pela ciência contemporânea, à medida que pensa ser capaz de reger-se por meio das questões apenas pelo uso da razão e que esta viria a ser o esperado antídoto contra o irracional dos mitos. Os mitos, ao contrário do que se pensa, não cessam sua atividade e sua pregnância graças ao esclarecimento da Razão.

A ação fundamental de um mito consiste em dar sentido ali onde não se tem nenhum e, com isso, garantir direção, ainda que essa direção não possa ser sustentada em termos lógico-racionais.

Não exageraríamos ao propor a biologização dos tempos atuais como nossa mitologia contemporânea. Afinal, ela nos trouxe a crença, suportada e mantida por seus exitosos milagres técnicos, na modificação da condição humana pela alteração genética, bioquímica, etc. Não precisaríamos mais dispensar esforços para a transformação social, mais custosa e incerta, porquanto passa pelo convencimento e pela relação com o outro.

As modificações biológicas são mais ágeis e mais controláveis, além de nos reconciliar com nosso sonho, deixado entre parênteses pela reflexão sociológica materialista, de nos aproximarmos da performance de Deus, sendo, como ele, criadores de seres novos no mundo. No lugar do homem livre, produto da conquista social, o super-homem, produto da mutação genética.

O lugar de destaque que as pesquisas biológicas gozam nos dias atuais não pode ser entendido, isoladamente, a partir dos seus avanços, conquistas e resultados, mas deve ser retomado desde a consideração mais ampla que envolve a política e a dramática inconsciente que o permite, garante e cimenta sua existência.

\footnotetext{
"Retomando o texto de Derrida, não é, por acaso, a política o modo como se dota uma comunidade para prevenir aquilo que põe em perigo seus cimentos? Deve-se estar aberto a todo acontecer?” (ALEMÁN, 2000, p. 82) [tradução livre]
} 
A hegemonia biológica na explicação da experiência humana não é um produto político novo da contemporaneidade. Tampouco o é o status destacado da figura do médico, corolário imediato dessa hegemonia.

Basta lembrarmos que a política nazista repousava fundamentalmente sobre uma teoria biologizante do ser humano (a que aferia a suposta supremacia da raça ariana) e que era revelador o número de médicos que aderiam, com seus serviços, voluntária e entusiasticamente, aos preceitos dessa política.

O impulso atual da perspectiva biologizante não deixa de retomar, de certo modo, a partitura na qual o nazismo escreveu sua música, pelo menos no que tange à idéia de que são os componentes biológicos que definem os comportamentos do homem.

A conhecida assertiva freudiana de que um dia se descobriria a causa orgânica para as neuroses, assertiva que ora é retomada como uma ironia, ora como uma esperança, ora como uma lamentação, parece ter encontrado seu tempo.

Os estados psíquicos em geral, de humor, de pensamento, de julgamento, etc. já são largamente descritos como resultantes de processos bioquímicos, e uma interferência química sobre eles é também largamente utilizada.

Uma população cada vez maior adere e reclama a boa nova trazida pelos remédios, que sugere efeitos mais rápidos do que aqueles obtidos pelo tratamento psicoterápico e sustenta para o indivíduo que seu sofrimento é uma doença de seu organismo e que é inútil procurar as razões dele em sua biografia particular.

O que cimenta esta política? De qual "acontecer" ela pretende prevenir-se?

Para entender a mudança que vem ocorrendo nos últimos anos na forma de redefinição dos sofrimentos humanos cotidianos - e não tão cotidianos -, é fundamental colocar em jogo a interseção das novas produções científicas com os novos procedimentos diagnósticos, o desenvolvimento e o marketing da indústria farmacêutica e a difusão, no senso comum, dos fundamentos biológicos do que é próprio do humano.

Não se trata de fazer frente a um desenvolvimento no campo científico que trouxe grandes contribuições para o tratamento dos sofrimentos psíquicos - nem tampouco advogar em favor do abandono das pesquisas biológicas -, mas exercer com cuidado a crítica de seus efeitos quando disseminados no espaço social como visão hegemônica da subjetividade. 
É um fenômeno de nossos tempos o aumento monumental do uso de medicamentos psicotrópicos. E não são poucos os autores que têm se debruçado sobre esse fato, analisando-o do ponto de vista das modificações do sistema capitalista, dos efeitos do consumo na vida subjetiva, das recodificações das experiências humanas em termos biológicos (DOMONT DE SERPA, 1998; BIRMAN, 1999; ROUDINESCO, 2000; AGUIAR, 2004; ROSE, N./DISPONÍVEL ON-LINE; GORI E DEL VOLGO, 2005; entre outros).

A partir da última metade do século $\mathrm{XX}$, as práticas em saúde e saúde mental tornaram-se crescentemente dependentes dos produtos farmacológicos. (ROSE, on-line) Desde então, os lucros da indústria farmacêutica têm crescido enormemente.

A história da produção das drogas psiquiátricas não é recente, inicia-se com o uso da clorpromazina, em 1952, em pacientes psicóticos, no hospital de Saint-Anne, na França. Desde então, as pesquisas em psicofarmacologia procuram a sintetização de drogas cada vez mais específicas e que tenham cada vez menos efeitos colaterais. Ao longo dos últimos 60 anos, encontramos no mercado novas versões dos tradicionais antipsicóticos, antidepressivos, ansiolíticos e dos psicoestimulantes. O marketing dos medicamentos promete efeitos cada vez mais precisos e ligados a sintomas também específicos de cada transtorno descrito na literatura médica.

As pesquisas sobre o funcionamento neuroquímico humano impulsionam e são impulsionadas pela indústria farmacêutica. O sistema de licença para produção e comercialização de drogas também atua nesse contexto, atento tanto aos efeitos terapêuticos quanto aos colaterais (neurológicos como de dependência) de cada nova droga desenvolvida. Mas a lógica do mercado também interfere no conjunto dessa mudança nas práticas em saúde, pois as indústrias farmacêuticas estão especialmente interessadas na venda de seus produtos. ${ }^{1}$

Para isso, tratam os remédios como qualquer outro produto, o que poderia parecer bastante estranho tempos atrás. A IMS Health é hoje, em todo o mundo, uma das maiores organizações comerciais de monitoramento da indústria farmacêutica. No site da IMS/Brasil, encontramos as seguintes afirmações:

Todas as maiores companhias do setor farmacêutico no mundo são clientes da IMS. Unindo experiência e competência, nós somos a escolha certa para ajudar a sua empresa a otimizar portfólios, assegurar o sucesso de novos lançamentos, gerenciar marcas e melhorar a eficácia da força de vendas. (...) 
Nosso negócio começa com as informações que coletamos numa escala inigualável. É o material bruto que coletamos de cerca de 29 mil fornecedores de dados em 225 mil localizações mundiais. Nós monitoramos 75\% dos medicamentos de prescrição em mais de 100 países, e $90 \%$ das vendas nos Estados Unidos. Nós acompanhamos mais de 1 milhão de produtos de mais de 3 mil fabricantes de medicamentos. Nós conduzimos auditorias médicas em mais de 45 países. Processamos 1 bilhão de transações por mês. (...) Hoje, com operações em mais de 100 países e uma receita anual de US\$2 bilhões, a IMS é a fonte de informação e análise líder mundial para qualquer um que deseje acompanhar, medir e ter sucesso na indústria farmacêutica. ${ }^{2}$

Com relação ao uso de medicamentos, os dados recolhidos por Rose $^{3}$ são significativos. Na década de 1990-2000, houve, nos Estados Unidos, aumento de $205 \%$ nas prescrições (considerando o número de doses mínimas utilizadas por medicamento) de antidepressivos e, no final da década, eles respondiam por $45 \%$ do total de prescrições para todas as drogas psiquiátricas. Para os antidepressivos de última geração (SSRI inibidores seletivos de recaptação de serotonina e SSNRI - inibidores seletivos de recaptação de serotonina e norepinefrina), verificou-se aumento de prescrição (também considerando o número de doses mínimas) da ordem de 1300\% durante o período de 1990-2001. Entre tais antidepressivos encontram-se o Prozac, o Zoloft e o Paxil (não disponível no Brasil).

"O medicamento psicotrópico só se transformou no que é", escreveu Édouard Zarafian, "por ter aparecido num momento oportuno. Tornou-se então símbolo da ciência triunfante - aquela que explica o irracional e cura o incurável”. (ZARAFIAN, E. apud ROUDINESCO, 2000. p. 23)

O poder dos remédios do espírito, portanto, é o sintoma de uma modernidade que tende a abolir no homem não apenas o desejo de liberdade, mas também a idéia mesma de enfrentar a adversidade. $O$ silêncio passa então a ser preferível à linguagem, fonte de angústia e vergonha. (ZARAFIAN, E. apud ROUDINESCO, 2000, p. 30)

A produção dos remédios (não somente os psiquiátricos) e seu uso não podem ser vistos somente no campo científico e da prática médica; os remédios atualmente produzidos apresentam-se como novos bens a consumir, atrelados à condição de produção de bem-estar, felicidade, auto-realização. Vejamos:

Vamos direto ao ponto: nos últimos 43 anos, o trabalho da EMS tem sido fabricar remédios. E, se rir é o melhor remédio, então podemos dizer que o trabalho da EMS tem sido fabricar sorrisos. Sorrisos de bem-estar, risos de 
alegria, gargalhadas de satisfação. (...) Deixando os números de lado, a EMS também encara a pesquisa científica muito a sério e mantém em Hortolândia, São Paulo, um dos maiores centros de pesquisa e desenvolvimento da América Latina, colocando no mercado cinco novos produtos por mês. E, graças a essa seriedade, a EMS foi eleita uma das marcas mais confiáveis entre os médicos. Por isso, sempre que você precisar de uma força e vir o logotipo azul da EMS, pode confiar. E depois, quando estiver tudo azul de novo, nem precisa dizer nada. Apenas responda com um sorriso. ${ }^{4}$

A direção da medicalização no mundo contemporâneo aponta, então, para uma descrição biológica das experiências humanas, para uma retradução de suas vicissitudes em termos sintomáticos, para uma intensificação do uso de medicamentos no alívio das dores cotidianas. A efetiva transformação no âmbito dos cuidados em saúde mental, embora mais estética do que conceitual, passou, sem dúvida, pelo uso das drogas psiquiátricas. No entanto, nosso olhar se dirige ao contexto mais amplo e à inclusão de uma lógica de cuidado apoiada no uso de medicamentos para uma gama muito maior de vivências humanas.

Com efeito, o medicamento não apareceu neste cenário como um simples prolongamento da perspectiva de tratamento que existia antes dele. Ele exigiu, ao adentrar o campo do tratamento dos males da alma, que a lógica se alterasse em função da nova perspectiva por ele oferecida. Sua perspectiva original, "re-mediar", trazer de novo para o nível médio, nunca esteve tão atual e ativa, embora este "pôr na média" agora assuma feições bem mais imprescindíveis.

Todo o caráter de "objeto criado para o consumo", destacado até aqui em nossa argumentação, precisa ser mais bem-explorado no que tange ao impacto desse "novo objeto", o remédio, no campo da vida psíquica.

O capitalismo, naquilo que a Psicanálise pôde extrair de sua operação discursiva, funciona "criando necessidades" que não existiam antes. $\mathrm{O}$ termo necessidade, aqui, tem um uso impróprio, uma vez que nada tem a ver com a idéia de necessidade.

De fato, é na medida em que opera com a lógica desejante (e não da necessidade), única que pode garantir o deslizamento infinito da atração pelos objetos do qual depende o capitalismo, que este faz sua fortuna. Se os homens fossem, como os animais, seres de necessidades, presos ao instinto, jamais sustentariam a pletora avassaladora de produtos criados em sua diversidade para agradar a todos os gostos.

De todo modo, ainda que contando com a lógica desejante, é buscando subvertê-la que a operação capitalista empreende seus maiores 
esforços. Isso porque pretende convencer que sempre há um "objeto sob medida" para você.

Quanto ao objeto do desejo, este é sempre escorregadio, jamais atingido, deixando uma insatisfação inevitável como seu rastro. O capitalista, como sabemos, pretende "não deixar nada a desejar", expressão popular cuja ambigüidade é digna de nota e não poderia jamais passar desapercebida ao ouvido atento do psicanalista.

Para tanto, sua lógica segue o percurso da "coisificação do objeto", sua fetichização, a proclamação de seus encantos sobre o sujeito.

Lacan (1992) menciona essa operação (embora só vá escrevê-la na grafia dos discursos pouco mais tarde) com o nome de Discurso do Capitalista, indicando com uma seta que vai do objeto direto para o sujeito sem barras ou impedimento, o que não aparece em nenhuma outra das formações discursivas formuladas por ele, sugerindo que, nesse domínio discursivo, trata-se de uma nova relação entre sujeito e objeto. Uma nova relação em que um inchaço do lugar de objeto traria uma conseqüente reclusão do lugar de sujeito.

O objeto, assim inflacionado, termina por convocar para o primeiro plano "o corpo e seus prazeres". O "goze", como imperativo de nosso tempo, implica, entre outras coisas, que o corpo, seja alçado ao primeiro plano.

A Psicanálise, desde sua concepção, está aparelhada para demonstrar como a constituição do sujeito depende, entre outras coisas, de uma operação de silenciamento do corpo/organismo. A entrada no mundo do sentido (linguagem) demanda certa queda do mundo das sensações (corpo), o que fica bastante bem-demonstrado pelos autistas, por exemplo, enquanto exaltam sua sensorialidade característica, assim constituída em detrimento da entrada na linguagem, feita, neste caso, de um modo bastante particular.

Ao mesmo tempo, a passagem do registro da necessidade para o da demanda e do desejo é outro modo de indicar teoricamente essa operação de silenciamento do corpo.

A recolocação do corpo/organismo em evidência, promovida pela biologização/medicalização, produto eminentemente capitalista, tem como corolário a diminuição do peso dado ao sujeito na experiência humana.

A retomada de uma lógica da necessidade, artificial, sem dúvida, já que o homem não perdeu sua condição desejante, recoloca o organismo e suas sensações também em primeiro plano. Se podemos dizer que a medicalização recoloca o corpo/organismo em evidência, não é só pela 
operação teórica, característica da Biologia, que toma o organismo como objeto, mas, principalmente, porque a utilização do remédio representa a busca da mudança no plano corporal, o da sensação. O "está se sentindo melhor" não raras vezes é base para o indicativo de cura e interrompe a elaboração de tudo o mais que a sensação pode mascarar.

Sabemos que a Psicanálise, por exemplo, define os parâmetros de uma cura não no plano sintomático, mas no fantasmático, exatamente pela compreensão que tem da lógica do sintoma psíquico. Lábil e migratório, porquanto atrelado a uma economia psíquica, sofre altos e baixos que não poderiam ser confundidos com sua dissolução. Confundir alívio e cura torna-se um expediente importante da medicalização da alma para impor sua perspectiva.

Em paralelo, a droga, seja lícita ou ilícita, segue sendo o objeto capitalista mais bem-sucedido, vide sua espetacular capacidade comercial, em parte, claro, graças à oferta de alteração sensorial que ela apresenta, mas também, fundamentalmente, porque consegue, melhor que qualquer outro produto capitalista, que o "sujeito se adapte" a ela.

Toda esta lógica tem inúmeros efeitos, mas nos interessa destacar, em particular, o impacto da promoção do objeto e do corpo ao primeiro plano em detrimento do campo da palavra.

A ordem simbólica faz de nós animais desnaturados pela linguagem, pela introdução de um gozo pulsional que substituiu a instintualidade animal; passando de um mundo de instintos para um mundo de pulsões, o ser humano perde e ganha; o que ganha é a faculdade de falar, é o mundo das palavras, o que perde é sua adequação às coisas, também sua adequação a si mesmo. (LEBRUN, 2004, p. 117)

Adaptar-se ao objeto, projeto por excelência do capitalismo, implica uma operação particular na linguagem que, como se vê na citação anterior, nasceu ao preço de nos desadaptarmos do objeto.

Medir esse impacto nos interessa particularmente pela possibilidade de refletirmos sobre nossa questão principal: a medicalização no universo escolar.

Para adentrarmos diretamente a questão da educação: $O$ que restaria a discutir com ou sobre uma criança diagnosticada como hiperativa para a qual o remédio já está prescrito? 


\section{IMPLICAC̣ÕES DA PRESENC̣A DO SABER MÉDICO NA EDUCAC̣ÃO}

Em trabalho recente ${ }^{5}$, analisamos a produção de um veículo da mídia destinada aos professores e constatamos que as informações oferecidas ao professor, especialmente nos últimos dez anos, contêm fortemente uma consideração biológica como fundamento para o entendimento tanto das vicissitudes do processo de escolarização de alguns, quanto para explicar o processo de aprendizagem. Perguntamo-nos se, do ponto de vista do ensino, veremos se organizar técnicas didáticas baseadas em tais considerações. Do ponto de vista de uma estimulação cerebral, talvez possamos pensar que a presença de um sujeito que educa e ensina pode não se fazer necessária. Se a estimulação cerebral for transformada em técnica, teremos uma mudança ainda mais radical na forma encontrada nos tempos atuais para configurar o espaço escolar. O lugar do sujeito que ensina e do sujeito que aprende ficaria aqui muito próximo do maquinal.

Quando analisamos, no mesmo veículo, os artigos que abordavam o Transtorno do Déficit de Atenção e Hiperatividade (TDAH), vimos ocorrer uma tradução de comportamentos típicos das crianças que foram muitas vezes abordados, do ponto de vista psicológico, até os anos 1990, como sintomas de uma doença. Ou melhor, encontramos uma tentativa de distinguir inquietação, indisciplina, agressividade, desatenção - que eram comumente abordados como problemas psicológicos -, de manifestações mais duradouras desses mesmos comportamentos, o que levaria a pensar na existência de uma doença. Ainda que os artigos tentem fazer essa distinção, ao final, acabam por traduzir tais comportamentos como sintomas e instalam a categoria TDAH como explicação de tais comportamentos nas crianças. A doença explicaria o não-aprendizado da criança.

Quando então o não-aprendizado se vê traduzido em termos biológicos, passível de correção pelo uso de medicamentos, o que poderemos dizer sobre os efeitos desse discurso?

Parece-nos que um primeiro efeito é o da desresponsabilização. $\mathrm{O}$ discurso sobre o organismo que falha parece deixar muito poucas brechas para que a educação seja vista como um laço entre adultos e crianças que possa resultar em algum tipo de transformação. A sujeição ao corpo orgânico reduz em muito a possibilidade de pensarmos nas dimensões simbólicas das relações educativas entre adultos e crianças. Assim, mais uma vez, há uma tendência ao esvaziamento do ato educativo e da densidade da experiência humana.

Além disso, se a solução para tal condição é o uso de remédios, a dimensão da técnica novamente se impõe. E essa dimensão, presente em 
muito no discurso pedagógico contemporâneo, estabelece uma lógica bastante diferente daquela que leva em conta a dimensão formativa da educação e a impossibilidade de garantias, antecipações e adequações da relação humana que a sustenta. Por outro lado, a crença no remédio como solução reduz outras intervenções na situação como potentes e transformadoras.

Esta medicalização da existência poderá se transformar numa ideologia totalitária, "fascista", apta a legitimar a administração das condutas individuais, a mistificação das massas, se em nome da ciência médica os viventes se encontrarem convertidos em um "fetichismo da mercadoria", "objeto industrial" conforme as novas normas sociais, morais e políticas. Assim, à "Indústria Cultural" analisada em seu tempo por Horkheimer e Adorno, se somará uma "indústria sanitária" esquadrinhando o espaço social e político do humano, prolongando a mecanização racional, despedaçante, calculadora e alienante do trabalho e do lazer. (GORI; DEL VOLGO, 2006, p. 20. Grifos dos autores) [tradução livre]

A presença do saber médico ou a tomada do saber médico pela pedagogia atual acompanha o que se vê em diversos outros âmbitos da rede social que habitamos - a validação de um discurso que toma a vida como um bem a ser glorificado, em suas formas maquinais, em sua capacidade estressante de trabalho, em sua toda potência e em sua plena felicidade.

Maud Mannoni, por exemplo, já levava isso em conta ao criticar as intervenções médico-psicológicas no campo educativo:

É a própria vida que seria preciso reinventar, mas a vida é uma palavra vaga e não se trata de tomar novamente Robinson por modelo; trata-se, outrossim, das instituições e, em primeiro lugar, da Família, da Escola e do Hospital. Em vez de revolucionar o ensino e sua estrutura, o Ocidente prefere, pelo contrário, remediar os efeitos das anomalias geradas por um ensino inadequado à nossa época. Remediar os efeitos significa, neste caso, encarregar a medicina de responder onde o ensino fracassou. (MANNONI, 1988, p. 49)

Apoiada num discurso médico em que o fenômeno subjetivo é visto pela lógica do funcionamento orgânico, a medicação aparece como reguladora da subjetividade, como elemento químico que reordena a desordem de um corpo não-adaptado a uma lógica discursiva que define ideais de produção e satisfação. Na contramão de uma consideração sobre a complexidade subjetiva, o saber médico atual faz parceria com a lógica 
do capitalismo que idealiza no consumo a fonte de uma satisfação irrestrita. O medicamento cai aqui como bem a consumir, atrelado ao discurso do bem-estar saudável, numa economia de puro prazer.

Pensando a partir da lógica capitalista, os medicamentos oferecem a exata adequação entre o que se transforma numa necessidade e aquilo de que se precisa para satisfazê-la - um objeto adequado às necessidades do sujeito. Ou seja, se as quantidades de dopamina, serotonina, etc. estão irregulares no organismo, é possível encontrar nos remédios a dose exata de solução para tal falha.

No âmbito da escolarização, os remédios aparecem como um recurso a mais para que o processo de aprendizagem das crianças possa ocorrer, pois o diagnóstico do transtorno já está validado.

Seria ilusório, no entanto, contabilizar essa entrada do remédio como uma soma, se considerarmos o que destacávamos antes como necessária modificação do universo que um novo objeto introduz.

Mais ainda, seria preciso destacar que a entrada do remédio se dá exatamente ali no lugar antes reservado ao professor, ou seja, não é o professor "mais" o remédio, senão que o remédio "menos" o professor. A menos que consideremos o papel de ministrar a medicação ou acompanhá-la como um papel docente, o que, por sua mera possibilidade, já indica a que ponto estamos perdidos na crise atual da responsabilidade, "respon'habilidade", habilidade em responder, quer dizer, não sabemos mais "a que respondemos".

O que pretendemos destacar aqui é que se a medicação vem responder ao porquê o menino aprende ou não aprende, ou ainda, vem se tornar um instrumento imprescindível na aprendizagem da criança, o professor "não tem mais nada a ver com isto", no duplo sentido que essa expressão indica: o de desresponsabilização e o de impotência. Essa relação costuma passar desapercebida, mas é a mesma operação que retira a responsabilidade que o faz, também, com a possibilidade de realizar algo.

Impotente porque irresponsável, o professor segue um destino sem perceber que o engendra, mas que o conduz a uma descaracterização de sua função precípua: a de ensinar. Se o aprendizado depende, em última instância, de fatores neuroquímicos, sobre os quais nada podemos fazer pela mediação da palavra, qual papel restaria ao professor?

Poder-se-ia objetar aqui dizendo que ao professor cabe continuar seu trabalho de sempre, agora tornado possível pela medicação nesses casos particulares, mas isso seria retomar a idéia de que um objeto entra para somar à lógica que está ali sem exigir nada de sua modificação. 
Apresentar a aprendizagem como um processo dependente de funções neuroquímicas esvazia, como salientávamos, a função do laço social.

Essa lógica que coloca o corpo/organismo em primeiro plano já tinha no campo escolar seu antecedente necessário: o paradigma behaviorista. Apesar das constantes discussões no âmbito metodológico da atual educação rodarem em torno da moda dita construtivista e as conseqüentes tentativas de dar uma aplicação institucional a elas, a instituição escolar continua, por uma série de fatores, mais inclinada a aderir, mesmo que não o saiba, ao behaviorismo reinante. Teoria hegemônica na América do Norte, parece ter tido seu momento de glória no Brasil para ver, em seguida, sua aparente queda, propiciada pela crítica ideológica de seus postulados, sempre identificados a uma supersimplificação do estudo do homem para fins manipulatórios.

Tal queda, entretanto, se pode ser flagrada no nível da aceitação e simpatia pelas teses behavioristas no universo da escola, não parece sustentar-se quando examinamos o cotidiano escolar, ainda repleto de ações que visam deliberadamente ao condicionamento do comportamento.

O ponto crucial desta questão não deve ser buscado no debate epistemológico com o behaviorismo, contexto em que suas razões não deixam de ter sustentabilidade, mas no campo ideológico, no qual podemos apreendê-lo em suas conexões com a legitimação científica de uma nova discursividade social (a capitalista) para a qual ele viria prestar seus serviços.

A lamentável verdade, no que concerne ao behaviorismo e a validade de suas 'leis', é que quanto mais pessoas há, mais eles têm a tendência de 'bem se conduzir' e de não suportar o não-conformismo. Na estatística, o fato é posto em evidência pelo nivelamento das flutuações. (...) A uniformidade estatística não é de modo algum um ideal científico inofensivo. (ARENDT, apud GORI; DEL VOLGO, 2006, p. 211) [tradução livre]

O que há de desagradável nas modernas teorias do comportamento, não é que elas sejam falsas, mas que elas podem se tornar verdadeiras, é que elas são, de fato, a melhor demonstração possível em conceitos de certas tendências evidentes da sociedade moderna. (ibidem, p. 214)

O crescimento e a concentração da população em grandes centros exigem a consideração das pessoas cada vez mais em bloco, donde o sucesso da teoria behaviorista como paradigma para a Psicologia que a sociedade atual estaria inclinada a melhor acolher. A naturalização do humano e a razão instrumental constituem os dois postulados funda- 
mentais dessa teorização, conforme analisamos em texto anterior (VOLTOLINI, 2007).

Deles reteremos apenas o essencial para nossa argumentação em torno da questão do impacto da medicalização sobre a educação. A conhecida tradição behaviorista de estudos com animais, de cujos resultados se espera extrair conseqüências de compreensão do comportamento humano, é um excelente exemplo dessa naturalização do homem, mas a pretensão de situar a Psicologia no rol das Ciências da Natureza também o é. Toda a tradição de reflexão sobre o homem como um ser "desnaturado", na qual a Psicanálise, entre outras, se situa, é negada deliberadamente e reputada como preconceituosa e obstaculizadora do desenvolvimento científico.

A negação da diferença entre o homem e o animal recoloca a problemática do corpo em primeiro plano, único campo em que a comparação seria possível, na mesma medida em que empalidece aquilo que marcaria a diferença essencial entre eles, a saber, a linguagem. Aqui retomamos o cerne da afirmação citada antes, de que o corpo só está em primeiro plano em detrimento da linguagem. De certo modo, a operação realizada pelo behaviorismo consiste em "esvaziar o psiquismo do psíquico", reduzindo-o ao organismo, como fica bem-comprovado em seu paradigma: $\mathrm{S}-\mathrm{R}$ (estímulo-resposta).

Não é casual que a teoria concebida com a ajuda do rato não leve em consideração o papel desempenhado pelo experimentador no resultado. Isso seria considerar que o "laço social" tem um peso na determinação da aprendizagem. O rato aprende graças a seus recursos particulares, de um lado, e graças à estratégia do experimentador, do outro, mas sem que a relação entre eles desempenhe qualquer papel. Estamos no topo da noção de Técnica, ícone da razão instrumental.

$\mathrm{Na}$ verdade, se o paradigma behaviorista pôde antecipar as condições para a entrada da medicalização nas escolas, foi apenas por sua vocação de pensar o homem como um objeto manipulável em seu comportamento, destituindo, assim, o caráter intersubjetivo da experiência educativa. Instaurou-se, então, a relação "saber-objeto", cara ao regime da Técnica, no lugar da relação intersubjetiva, inerente ao campo educativo.

A ciência, ao tomar o homem como parte da natureza, pode fazer um uso dele do mesmo modo que justifica o uso que faz dela. É claro que entram aqui as reflexões éticas do uso das descobertas científicas, o que só escancara o problema, uma vez que as tais reflexões só entram neste ponto porque não estavam na origem do empreendimento investigativo. 
Podemos controlar eticamente o uso dos medicamentos nas escolas para que eles sirvam apenas aos melhores fins, mas isso deixa intocada a mudança que esses tais "melhores fins" trouxeram em seu bojo, tal como o cavalo de tróia?

O que circula hoje como saber médico no social se assemelha a um conjunto de procedimentos, uma medicina remediativa, sem moralizações para o futuro. Muito mais pautada no controle da vida cotidiana, numa prática de hábitos no presente. No mundo contemporâneo, o apelo aos remédios é expressão das maneiras encontradas na cultura para negar um mal-estar estrutural.

O cientificismo atual permite a construção de que tudo é possível, negando a impossibilidade como limite estrutural do homem, buscando traduzi-la em impotência que um dia poderá ser superada ou com esforço pessoal, ou com as novas conquistas tecnológicas ou com a adesão de cada um a um governo de si que leve em conta os ideais contemporâneos de saúde e busca pelo bem-estar pleno.

Em seu texto o Mal-estar na civilização (1930), Freud constata a inquietação dos homens diante da descoberta de que haviam criado pelo próprio uso da Razão, atributo que lhes conferira uma supremacia indiscutível sobre os "limites que a natureza lhe impusera", instrumentos com os quais poderiam pôr fim a sua própria existência na Terra. Seu decorrente mal-estar viria da convicção íntima de que já não podiam mais confiar cegamente na justeza de sua Razão nem mais controlar integralmente o destino dos objetos por eles criados a ponto de impedi-los de "ganhar autonomia" em relação à própria vontade do criador. (...) é a mesma questão também que retorna na perspectiva do remédio criado para "resolver" o problema da impotência masculina, que garante uma "ereção sem sujeito". Ainda que ele possa fazer algo para obtêla nada pode fazer para eliminá-la, a não ser agüentar que os efeitos do remédio, que agora está no comando, sigam seu ciclo normal.

Ocasião para percebermos um paradoxo interessante: o quanto um "sem-limites" que o exercício da Razão nos levou, se foi capaz de nos emancipar dos limites impostos pela Natureza, não pode, entretanto, nos livrar de desembocar num outro limite agora imposto pela própria lógica do objeto criado por nós. O sonho acalentado por séculos, que a construção de objetos pudesse nos dispensar da labuta, realiza na contemporaneidade sua faceta inusitada: a do risco de que eles nos dispensem de tudo. (VOLTOLINI, 2007, p. 120)

A re-tradução de nossa subjetividade em termos neuroquímicos abre espaço para um abandono da dimensão simbólica de nossa constituição como sujeitos e reduz nossa condição crítica em relação ao mundo em que vivemos. Certo reducionismo ao biológico é também "a possibi- 
lidade, para um sujeito, de ser aliviado do mal-estar da incerteza inerente ao fato de pensar e sustentar seu desejo em sua singularidade, remetendo exclusivamente aos enunciados" (LEBRUN, 2004, p. 73). Também nos convida a nos afastarmos da idéia de que convivemos, como humanos, com uma dimensão do impossível, ou seja, não há garantias para o futuro, não há garantias de satisfação, não há antecipação possível daquilo que um encontro possa nos fazer viver e isso não coincide com impotência.

É justamente no reconhecimento do limite que a dimensão criativa pode existir. Mas se concordarmos em somente remediar nossas impossibilidades, talvez estejamos também reduzindo as possibilidades de inventarmos formas possíveis de viver neste mundo.

\section{NOTAS}

${ }^{1}$ Para uma análise precisa da história de desenvolvimento dos psicofármacos e suas implicações na prática psiquiátrica, bem como do contexto apontado, ver Rose, $\mathrm{N}$. Becoming Neurochemical Selves. Disponível on-line. Também publicado em Stehr, N. (Org). Biothechnology: Between commerce and civil society. The State University. New Jersey: Transaction Publishers, 2004.

${ }^{2}$ Disponível em:

http://www.imshealth.com/web/channel/0,3147,76876394_76978451_76989188,00.html>.

3 Os dados utilizados por Rose foram obtidos junto ao IMS Health e a International Narcotics Contral Board.

4 Propaganda encontrada em uma revista mensal de grande circulação, também disponível no site da EMS. A EMS- sigma é um laboratório de sintetização de genéricos, segundo maior laboratório farmacêutico do Brasil. (Fonte: Comunidade Virtual de Vigilância Sanitária/BVS: Bibliotaca Virtual em Saúde)

${ }^{5}$ Trata-se da dissertação de mestrado de Guarido, RL. "O que não tem remédio, remediado está": medicalização da vida e algumas implicações da presença do saber médico na educação. Dissertação (Mestrado em Educação) Faculdade de Educação da Universidade de São Paulo, São Paulo, 2008.

\section{REFERÊNCIAS}

AGUIAR, A. A. A psiquiatria no divã: entre as ciências da vida e a medicalização da existência. Rio de Janeiro: Relume Dumará, 2004.

ALEMÁN, J. Jacques Lacan y el debate posmoderno. Buenos Aires: Filigrana, 2000.

ARENDT, H. A crise na educação. In: ARENDT, H. Entre o passado e o futuro. 5 ed. São Paulo: Perspectiva, 2003. p. 221-247.

ARIÈS, P. História social da criança e da família. 2 ed. Rio de Janeiro: LTC Editora, 1981. BIRMAN, J. Mal-estar na atualidade: a psicanálise e as novas formas de subjetivação. Rio de Janeiro: Civilização Brasileira, 1999. p. 175-193.

CALIMAN, L.V. Dominando corpos, condu₹indo açôes: genealogias do biopoder em Foucault. 
2001. Dissertação (Mestrado em Saúde Coletiva). Instituto de Medicina Social da Universidade do Estado do Rio de Janeiro. Rio de Janeiro, 2001.

COSTA, J. F. Ordem médica e norma familiar. [1979]. 5 ed. Rio de Janeiro: Graal, 2004.

DOMONT DE SERPA, O. Mal-Estar na Natureza. Belo Horizonte: Te Cora, 1998.

DONZELOT, J. A polícia das famílias. 3 ed. São Paulo: Graal, 2001.

FOUCAULT, M. História de la medicalización. Educación médica y salud, v. 11, n. 1, p. 3 25, 1977.

FOUCAULT, M. A crise atual da medicina. Reprodução de conferência pronunciada por Michel Foucault na Escola de Saúde Pública do Rio de Janeiro, 1974. (Mimeogr. sem paginação)

FOUCAULT, M. O nascimento da medicina social. In: Microfísica do poder. 3 ed. Rio de janeiro: Graal. 1982. p. 193 -207.

FOUCAULT, M. A política da saúde no século XVIII. In: Microfísica do poder. 3 ed. Rio de janeiro: Graal. 1982. p. 79-98.

FOUCAULT, M. Vigiar e punir: nascimento da prisão. 29 ed. Petrópolis: Vozes, 1987.

GORI, R.; DEL VOLGO, M-J. La Santé totalitaire: essai sur la médicalisation de l'existence. Paris: Denoël, 2005.

KUPFER, M. C. M. Educação para o futuro: psicanálise e educação. São Paulo: Escuta, 2001.

LACAN, J. O seminário livro 17: O avesso da Psicanálise. Rio de Janeiro: J.Z.E., 1992.

LAJONQUIÈRE, L. Infância e ilusão (psico)pedagógica: escritos de psicanálise e educação. Petrópolis, RJ: Vozes, 1999.

LEFORT, C. Formação e autoridade: a educação humanista. In: LEFORT, C. Desafios da escrita política. São Paulo: Discurso, 1999. p. 207-223.

LEGNANI, V. N; ALMEIDA. S.F.C. A construção da infância: entre os saberes científicos e as práticas sociais. Estilos da Clínica: Revista sobre a infância com problemas, São Paulo, v. 9, n. 16, p. 102-121, 2004.

LEBRUN, J-P. Um mundo sem limite: ensaio para uma clínica psicanalítica do social. Rio de Janeiro: Companhia de Freud, 2004.

MANNONI, M. Educação impossivel. Rio de Janeiro: Francisco Alves, 1988.

MOYSÉS, M.A.A. A institucionalização invisivel: crianças que não-aprendem-na-escola. Campinas, SP: Mercado de Letras; São Paulo: Fapesp, 2001.

PATTO, M.H.S. A produção do fracasso escolar: historias de submissão e rebeldia. São Paulo: T.A. Queiroz Editor, 1993. p. 7-127.

PATTO, M.H.S. Ciência e política na primeira república: origens da psicologia escolar. Clio-Psyché, Uerj, Nape, 1999. Disponível em: <www2.uerj.br/ cliopsyche/site/livros/clio1/livroclio1.htm>. Acesso em: setembro/2005.

ROSE, N. Becoming Neurochemical Selves. Disponível em: <http://www.springerlink.com/content/qm2c3r90rkx2tepj>. Acesso em 26/07/2007. ROUDINESCO, E. Por que a psicanálise? Rio de Janeiro: Jorge Zahar, 2000.

SILVA, F.L. O mundo vazio: sobre a ausência da política no contexto contemporâneo. In: SILVA, D.A.; MARRACH, S.A. (Orgs.). Maurício Tragtenberg. Uma vida para as ciências humanas. São Paulo: Editora da Unesp. 2001. p. 239-250.

VOTOLINI, R. A relação professor-aluno não existe: corpo e imagem, presença e distância. ETD - Educação Temática Digital, Brasília, DF, 8.0, p. 119-139, jun. 2007. Disponível em: <http://143.106.58.55/revista/viewarticle.php?id=415>. Acesso em 09/10/2007. 
Recebido: 07/09/2008

Aprovado: 09/10/2008

\section{Contato:}

FE-USP

Av. da Universidade, 308, B1 B

Cidade Universitária

São Paulo - SP

05508-040 